\title{
Sodium and Potassium Currents Influence Wallerian Degeneration of Injured Drosophila Axons
}

\author{
Bibhudatta Mishra, Ross Carson, Richard I. Hume, and Catherine A. Collins \\ Department of Molecular Cellular and Developmental Biology, University of Michigan, Ann Arbor, Michigan 48109-1048
}

Axons degenerate after injury and in neuropathies and disease via a self-destruction program whose mechanism is poorly understood. Axons that have lost connection to their cell bodies have altered electrical and synaptic activities, but whether such changes play a role in the axonal degeneration process is not clear. We have used a Drosophila model to study the Wallerian degeneration of motoneuron axons and their neuromuscular junction synapses. We found that degeneration of the distal nerve stump after a nerve crush is greatly delayed when there is increased potassium channel activity (by overexpression of two different potassium channels, Kir2.1 and dORK $\Delta$-C) or decreased voltage-gated sodium channel activity (using mutations in the para sodium channel). Conversely, degeneration is accelerated when potassium channel activity is decreased (by expressing a dominant-negative mutation of Shaker). Despite the effect of altering voltage-gated sodium and potassium channel activity, recordings made after nerve crush demonstrated that the distal stump does not fire action potentials. Rather, a variety of lines of evidence suggest that the sodium and potassium channels manifest their effects upon degeneration through changes in the resting membrane potential, which in turn regulates the level of intracellular free calcium within the isolated distal axon.

\section{Introduction}

Axons are long, hence vulnerable components of neuronal circuits. An axon whose connection with the cell body has been compromised degenerates via an active self-destruction program called Wallerian degeneration. The cellular mechanism of Wallerian degeneration is still poorly understood, yet it appears to share similarities to axonal degeneration in neuropathies and neurodegenerative diseases (Coleman, 2005), hence there is much interest in determining the factors that lead to its initiation.

Axons that have lost connection to their cell bodies do not degenerate immediately. Rather, there is a lag phase, which ranges from hours to days in vertebrates and up to months in some invertebrates, depending upon the cell type and also upon temperature (Birks et al., 1960; Hunt and Nelson, 1965; Miledi and Slater, 1970; McDonald, 1972; Luttges et al., 1976; Lubińska, 1977; Bittner, 1991; Chaudhry and Cornblath, 1992; Tsao et al., 1999; Xiong and Collins, 2012). During this lag phase, the axonal membrane remains fully intact, and is able to conduct action potentials if stimulated. The excitable and conductive properties of distal axons appear to change with time after injury (LoPachin

Received March 6, 2013; revised 0ct. 11, 2013; accepted Oct. 17, 2013.

Author contributions: B.M., R.C., and C.A.C. designed research; B.M. and R.C. performed research; B.M., R.C., R.I.H., and C.A.C. analyzed data; B.M., R.C., R.I.H., and C.A.C. wrote the paper.

This work was supported by the National Institute of Health (Grant NS069844). We thank Jennifer Diep, Travis Washington, Emily Han, Leni Truong, James Schutt, Pushpanjali Soppina and Nicolette Ognjanovski for technical assistance; and John Kuwada, Michael Sutton, and Jiaxing Li for helpful discussions. We thank Haig Keshishian, Richard Baines, and Barry Ganetzky for Drosophila lines. We also thank the Bloomington Stock Center (Indiana University), and the Developmental Studies Hybridoma Bank (University of lowa).

The authors declare no competing financial interests.

Correspondence should be addressed to Dr Catherine Collins, University of Michigan, 830 North University Avenue, Ann Arbor, MI 48109-1048.E-mail: collinca@umich.edu.

DOI:10.1523/JNEUROSCI.1007-13.2013

Copyright $\odot 2013$ the authors $\quad 0270-6474 / 13 / 3318728-12 \$ 15.00 / 0$ et al., 1990; Moldovan et al., 2009). However, whether such changes functionally influence the process of axonal degeneration has not been addressed.

Axotomy induces a brief burst of action potentials (Ambron and Walters, 1996; Abegg, 2007), but then distal axons of most neuronal types are silent, because they are separated from initiating signals in the cell body. These changes in activity are also coupled to changes in synaptic activity. The injury-induced burst of action potentials can induce a burst of neurotransmitter release (Abegg, 2007), but then, once separated from the cell body, the presynaptic terminals from distal "stumps" release very little neurotransmitter. Such changes could potentially serve as a signal that the distal axon is not functional and should degenerate. Alternatively, changes in the excitability of the distal axon could lead to ionic imbalances that ultimately trigger axonal degeneration. A number of studies suggest that altered membrane properties and ionic imbalances play an important role in axonal degeneration after anoxic injury and in multiple sclerosis (Stys, 2005; Waxman, 2006). Whether neuronal and/ or synaptic activity plays a role in Wallerian degeneration has not been addressed.

Here we have used an injury model in third instar Drosophila larvae to investigate whether neuronal excitability influences the mechanism of Wallerian degeneration. An advantage of this peripheral nerve crush injury model is that the neuromuscular junction (NMJ) synapses formed by the injured motoneurons are amenable to a number of manipulations and assays, including high-resolution imaging and electrophysiology (Keshishian et al., 1996; Budnik et al., 2006). This creates an ideal scenario for characterizing the changes in neuronal and synaptic activity after injury, and the roles these play in the degeneration mechanism. 


\section{Materials and Methods}

Fly stocks. The following strains were used in this study: Canton-S (wildtype), OK6-Gal4 (Aberle et al., 2002), UAS-Kir 2.1(Baines et al., 2001), UAS-dORK $\Delta$-C (Nitabach et al., 2002), m12-Gal4 (Ritzenthaler et al., 2000), SDN (Mosca et al., 2005), para $^{\text {ts1 }}$ (Siddiqi and Benzer, 1976; Wu and Ganetzky, 1980), and para ${ }^{\text {ST76 }}$ (Siddiqi and Benzer, 1976). UASpara-RNAi and UAS-moody-RNAi lines were obtained from the Bloomington stock center, (BL31471, BL31676, and BL36821).

Nerve crush assay. As described by Xiong et al. (2010) and Xiong and Collins (2012), the segmental nerves of third instar larvae were visualized through the cuticle under a standard dissection stereomicroscope. Although larvae were anesthetized with $\mathrm{CO}_{2}$ gas, the segmental nerves were pinched tightly through the cuticle for $\sim 5 \mathrm{~s}$ with Dumostar no. 5 forceps. After successful injuries, the posterior halves of the larva were paralyzed. Larvae were then transferred to a grape plate and kept alive for varying periods of time at $25^{\circ} \mathrm{C}$.

Immunocytochemistry. Wandering third instar larvae were dissected in ice-cold PBS and fixed in either 4\% paraformaldehyde in PBS or Bouin's fixative for 15-30 min, depending on the antibodies used. Antibodies were used at the following dilutions in PBS with 5\% normal goat serum: Cy3 goat anti-HRP, 1:500 (Jackson ImmunoResearch Laboratories), A488 rabbit anti-GFP, 1:1000 (Invitrogen), and mouse anti-Futsch, 1:100 (Developmental Studies Hybridoma Bank). For secondary antibodies, Cy3- and A488-conjugated goat anti-rabbit and anti-mouse (Invitrogen) were used at 1:1000. All samples were mounted and imaged in vectashield (Vector Laboratories).

Imaging. Confocal images were collected at room temperature on an Improvision spinning disk confocal system, consisting of a Yokagawa Nipkow CSU10 scanner, and a Hamamatsu C9100-50 EMCCD camera, mounted on a Zeiss Axio Observer with $25 \times(0.8 \mathrm{NA})$ multi and $40 \times$ (1.3 NA), $63 \times(1.5 \mathrm{NA})$, and $100 \times(1.46 \mathrm{NA})$ oil objectives. Similar settings were used to collect all compared genotypes and conditions. Volocity software (PerkinElmer) was used for all image acquisition.

Changes in intracellular $\mathrm{Ca}^{2+}$ in the distal stump of injured axons over time were studied by live imaging of the genetically encoded $\mathrm{Ca}^{2+}$ indicator GCaMP3.0 (Tian et al., 2009), which was expressed in motor neurons using the OK6-Gal4 driver. At different time points after injury, larvae were dissected in HL3 (containing either $1 \mathrm{mM} \mathrm{CaCl}_{2}$, or for Fig. $8 E, 0 \mathrm{mM} \mathrm{CaCl}_{2}$ and $1 \mathrm{~mm}$ EGTA), and then pinned to an agar plate with a coverslip. Segmental nerves were imaged $\sim 150 \mu \mathrm{m}$ distal to the injury site. For Figure $8 D$, the same region was imaged every $15 \mathrm{~min}$ for a total of not $>3 \mathrm{~h}$ per animal: confocal images from $15 \mathrm{~min}$ to $3 \mathrm{~h}$ after injury; $2-5,3-6,5-8$, and $7-9.5 \mathrm{~h}$ after injury were collected and merged from a total of 24 axons from 14 animals. The average GCaMP3.0 intensity was measured and average background intensity was subtracted using Volocity software, and normalized to the average GCaMP3.0 intensity in uninjured animals.

Quantification of degeneration. To quantify axonal degeneration, we scored, while blind to genotype, the fragmentation of $\mathrm{m} 12-\mathrm{Gal} 4$, UASmCD8: GFP labeled axons within segmental nerves $150 \mu \mathrm{m}$ distal to the injury site according to one of five categories between 0 and $100 \%$ (with $100 \%$ meaning completely fragmented) as described by Xiong and Collins (2012). All measurements indicate the average from multiple axons $(n \geq 20)$. To quantify the extent of degeneration of the NMJ, we measured disappearance of Futsch from NMJ boutons. This MAP1B homolog binds stable microtubules, which in uninjured axons extend through all but the most terminal boutons (Hummel et al., 2000; Roos et al., 2000). The NMJ degeneration index is defined as the length of NMJ without Futsch staining divided by the total length of the nerve terminal, which is determined by anti-HRP staining. Total lengths were measured using the simple neurite tracer plugin of ImageJ software. One-way ANOVA followed by Tukey's post hoc test was used for statistical analysis.

Electrophysiology. Intracellular recordings were made from muscle 6 in segments A3 and A4 of third-instar male larvae. The larvae were visualized with oblique illumination on an Olympus BX51W1 fixed stage upright microscope with a $10 \times$ water-immersion objective. Sharp electrodes (15-25 M 2 ), made of borosilicate glass (outer diameter $1.2 \mathrm{~mm}$ ) were filled with $3 \mathrm{M} \mathrm{KCl}$. The signal was amplified with a Geneclamp 500B
(Molecular Devices), digitized with a Digidata 1322A interface (Molecular Devices), and stored on a PC with pClamp 10.2 (Molecular Devices). The animals were dissected with phosphate buffer saline and replaced with recording solutions (HL3; Stewart et al., 1994) just before recording. HL 3 contained the following (in mM): $70 \mathrm{NaCl}, 5 \mathrm{KCl}, 20 \mathrm{MgCl}_{2}, 10$ $\mathrm{HCO}_{3}, 5$ trehalose, 115 sucrose, $5 \mathrm{HEPES}, 1 \mathrm{CaCl}_{2}$; the $\mathrm{pH}$ was adjusted to 7.2. The dissection and recording conditions were the same for larvae with intact, cut, and crushed axons. To block voltage-gated sodium channels pharmacologically, a $1 \mu \mathrm{M}$ final concentration of tetrodotoxin (TTX) was added to the HL3 saline, and recordings were made after a 5 min incubation period.

To elicit evoked excitatory junction potentials (EJPs), the nerve was drawn into a tight-fitting suction electrode and stimulated with brief (1 $\mathrm{ms}$ ) depolarizing pulses controlled with a Digidata interface. Because two excitatory axons innervate muscle 6 , recordings of evoked responses were typically performed with two different stimulus amplitudes. The lower amplitude was set to a level that produced postsynaptic responses 25 $50 \%$ of the time. Traces without responses were taken to be failures to achieve threshold, because the smallest responses obtained were several times larger than the spontaneous miniature potentials observed in the absence of stimulation. The reason for using this level was to accurately estimate the amplitude of responses to stimulation of the lower threshold axon; stimuli that activated the lower threshold axon $100 \%$ of the time also occasionally activated the higher threshold axon. The second stimulus amplitude was set to $125 \%$ of the lowest amplitude that sometimes elicited spikes from the higher threshold axon; based on the amplitude of the responses this stimulus level activated both axons on every trial.

For analysis of evoked responses, 100 events per cell recorded at $0.2 \mathrm{~Hz}$ were measured using the cursor feature in Clampfit 10.2 (Molecular Devices) and then averaged. For analysis of spontaneous miniature EJPs, at least 50 consecutive events were measured per cell using MiniAnal (Synaptosoft). Miniature EJP ( $\mathrm{mEJP}$ ) frequency was calculated from the first $45 \mathrm{~s}$ of recording time. For all genotypes the resting membrane potentials and input resistances were similar, with average resting potentials of $-73 \pm 4$ and input resistances of $6 \pm 0.2 \mathrm{M} \Omega$.

Ex vivo assay. Third instar larvae were rinsed in distilled water, and then subjected to the nerve crush injury as described above. After injury, the larvae were dissected and pinned in a Sylgard dish in HL3 saline solution (containing $1 \mathrm{mM} \mathrm{CaCl}_{2}$ ). During the dissection, only the nervous system and muscle tissue of the body wall were left intact; all other organs were removed from the animal and discarded. The dissected larvae were left pinned to the dissection plate and incubated at $25^{\circ} \mathrm{C}$ (or where indicated, $37^{\circ} \mathrm{C}$ ) in $\mathrm{HL} 3$ until the desired time point was reached. After incubation, the preparation was rinsed quickly with PBS immediately before fixation and antibody staining. For the ex vivo blockade of voltage gated sodium channels, the HL3 saline contained $1 \mu \mathrm{M}$ TTX. For inhibition of potassium channels, the HL3 saline contained $6 \mathrm{~mm}$ 4-aminopyradine (4-AP).

\section{Results}

Changes in potassium channel expression influence the initiation of axonal and synaptic degeneration after injury

It is well documented that injured axons undergo changes in excitability and firing rate over time (Kuwada and Wine, 1981; Titmus and Faber, 1990; Walters et al., 1991; Moldovan et al., 2009); however, most studies have focused upon the cell body and proximal stump. The changes that take place in the distal stump and their contribution(s) to the degeneration of injured axons are less clear. Using genetic methods to manipulate the excitability of single motoneurons in Drosophila larvae, we have investigated whether changes in excitability affect the degeneration of axons and synapses after acute mechanical injury in vivo.

We first generated animals in which a small subset of motoneurons were chronically silenced by expression of Kir2.1, a rectifying $\mathrm{K}^{+}$channel that alters the resting membrane potential below the threshold required to fire action potentials (Johns et al., 1999; Hodge, 2009). UAS-Kir2.1 (Baines et al., 2001) was coex- 
pressed with UAS-mCD8::GFP using the $\mathrm{m} 12-\mathrm{Gal} 4$ driver, which drives expression in only two motoneurons per hemisegment (Ritzenthaler et al., 2000; Xiong et al., 2010). Using GFP to visualize single axons within larval segmental nerves, we observed that control axons became completely fragmented within $20 \mathrm{~h}$ after injury (Xiong and Collins, 2012; Fig. 1A). In contrast, the silenced neurons that expressed Kir2.1 did not degenerate by the end of the $44 \mathrm{~h}$ window of time before the animals pupated (Fig. 1A), whereas adjacent neurons in the injured nerve degenerated at the same rate as in untreated larvae (Fig. 1B). Supporting the interpretation that neuronal silencing inhibits axonal degeneration, neurons expressing the constitutively open Drosophila rectifying $\mathrm{K}^{+}$channel, dORK $\Delta-\mathrm{C}$ (Nitabach et al., 2002) also failed to degenerate after injury (data not shown).

For the converse manipulation, increasing the excitability of the same motoneurons, we expressed a dominant-negative mutation in the Shaker $\mathrm{K}^{+}$channel, UASSDN (Mosca et al., 2005), using the same $\mathrm{m} 12-G a l 4$ neuronal driver. The Shaker regulated $\mathrm{K}^{+}$current plays a key role in regulating the membrane excitability of neurons (Jan et al., 1977; Tanouye et al., 1981; Ganetzky and $\mathrm{Wu}, 1982$ ). Previous studies indicate that motoneurons expressing the SDN mutation exhibit phenotypes of reduced $\mathrm{K}^{+}$channel function and hyperexcitability, including elevated evoked and spontaneous neurotransmitter release (Ganetzky and $\mathrm{Wu}$, 1983; Mosca et al., 2005). In contrast to the electrically silenced neurons, neurons expressing SDN exhibited a faster time course of degeneration after injury (Fig. $1 B$ ).

To quantify the degeneration at the NMJ, we took advantage of the fact that the axonal membrane epitopes recognized by anti-HRP antibodies are cleared very slowly from synapses undergoing Wallerian degeneration (Xiong and Collins, 2012). The anti-HRP staining was therefore used to estimate the length of the original synaptic bouton arbor. Many other presynaptic proteins disappear completely from degenerating synapses within 24 h of injury (Xiong and Collins, 2012), so we measured the extent of the presynaptic arbor using one such marker, the microtubule binding protein Futsch (Hummel et al., 2000; Roos et al., 2000). Synapses formed by motoneurons expressing SDN initiated degeneration at an earlier time point than control synapses (Fig. 1C). The extent of degeneration that is normally seen at $16 \mathrm{~h}$ at control synapses was observed at $8 \mathrm{~h}$ in SDN mutants (Fig. 1D). Together with the effects of neuronal silencing, these results suggested that the excitable properties of the neuronal membrane could strongly influence the rate of axonal degeneration.

\section{Acute "silencing" delays axonal and synaptic degeneration} The above genetic manipulations induced chronic silencing or hyperexcitability in motoneurons. To address whether membrane

B
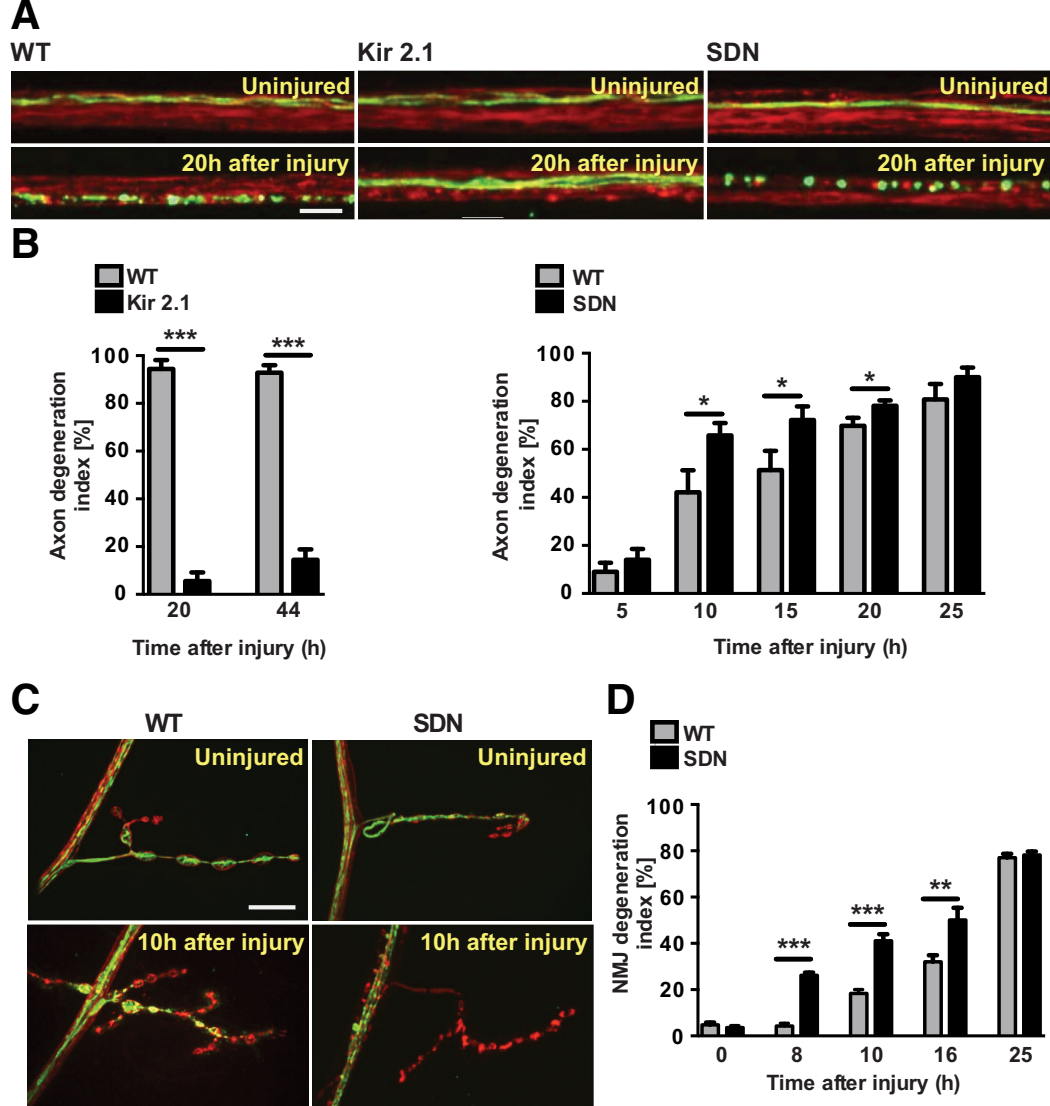

D

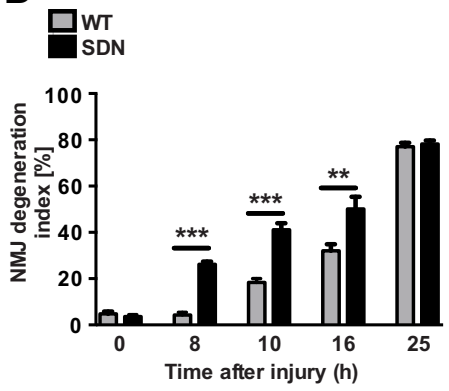

Figure 1. Electrically silent neurons do not degenerate while hyperexcitable neurons degenerate faster. $\boldsymbol{A}$, The Gal4/UAS was used to express UAS transgenes specifically in two fasciculated motoneurons (using the m12-Gal4 driver; Ritzenthaler instar larvae were coimmunostained for GFP (green) and the neuronal MAP1B homolog Futsch (red). B The extent of axonal degeneration at different time points after injury was quantified by scoring the axon degeneration index as described in Materials and Methods; $n \geq 20$ axons for each condition and genotype. Genotypes used: WT [m12-Gal4, UAS-mCD8::GFP/+ (Canton S

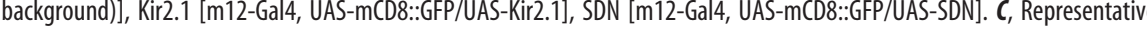
Materials and Methods; $n \geq 20$ NMJs for each condition and genotype. Error bars represent SEM. ${ }^{*} p<0.05,{ }^{* *} p<0.01$, ${ }^{* * *} p<$ 0.001 , based on one-way ANOVA with Tukey's post hoc test.

excitability before, during, or after injury could influence degeneration, we used conditional alleles of the voltage-gated sodium channel subunit, para. The para $^{\text {ts }}$ mutations have been well characterized for their ability to acutely alter neuronal excitability (Suzuki et al., 1971; Siddiqi and Benzer, 1976; Wu and Ganetzky, 1980; O'Dowd et al., 1989; Loughney et al., 1989). In these mutants, action potentials are blocked (and animals are paralyzed) at the elevated nonpermissive temperature (Siddiqi and Benzer, 1976; Wu and Ganetzky, 1980; Ganetzky et al., 1986). We treated para $^{\text {tsl }}$ and wild-type control animals with the five paradigms outlined in Figure $2 A$, and visualized the degeneration of GFP-labeled single motoneurons. In all paradigms, including $6 \mathrm{~h}$ shifts to the nonpermissive temperature, animals recovered motility in noninjured parts of the body within seconds of returning to the permissive temperature.

Shifting para mutants to the nonpermissive temperature either before or during the injury had no effect upon the rate of degeneration compared with controls (Fig. $2 A a, A c$ ). In con- 
A

(a) Unshifted-injured

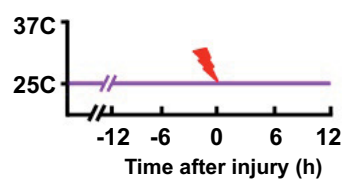

(c) Shifted to $37 \mathrm{C}$ during injury

(d) Shifted to $37 \mathrm{C}$ after injury
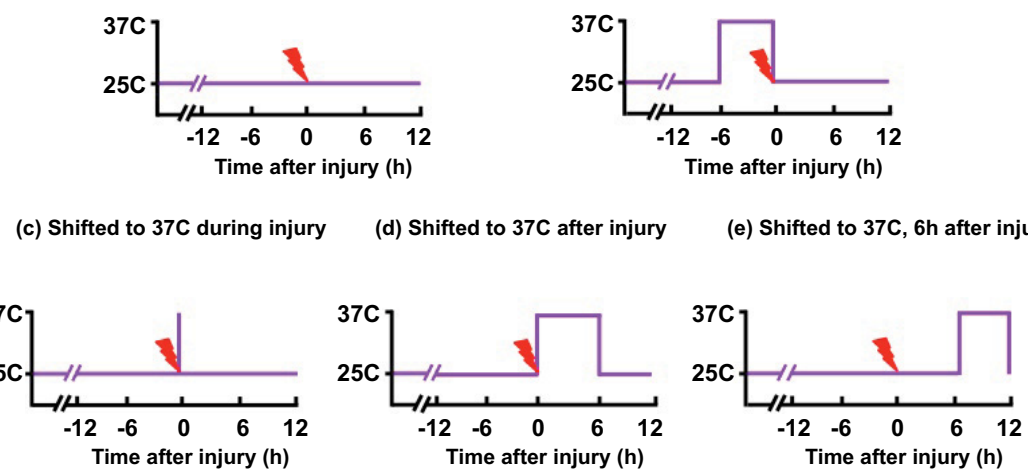

B

\section{Condition a}

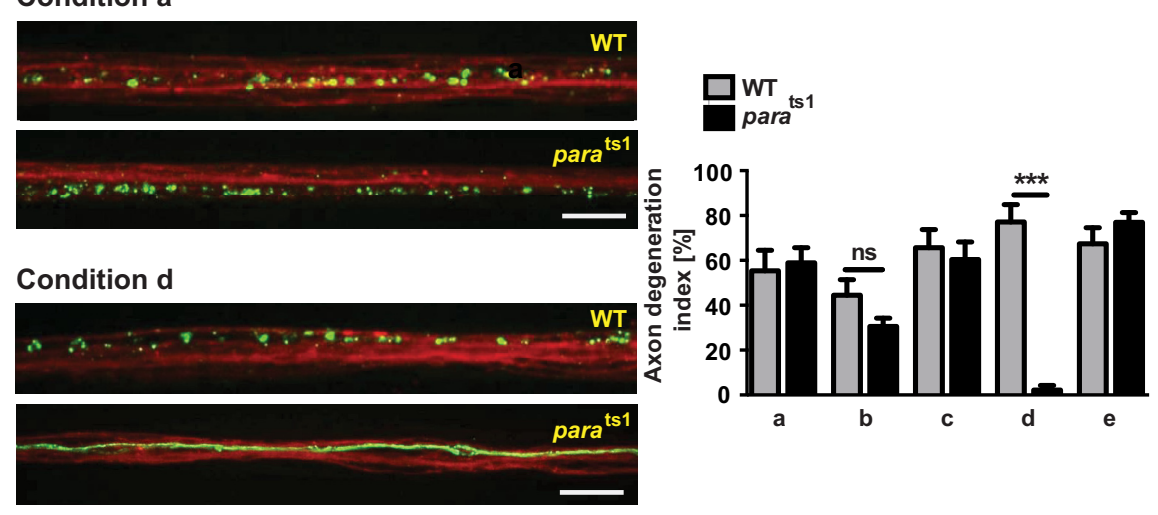

Figure 2. Acute silencing after injury delays axonal degeneration. $A$, Schematic for neuronal silencing at different time points with respect to injury (indicated by the lightning bolt). WT and para ${ }^{\text {ts } 1}$ larvae were subjected in parallel to the following paradigms: $\boldsymbol{A a}$, a constant temperature of $25^{\circ} \mathrm{C} ; \boldsymbol{A b}$, shifted to $37^{\circ} \mathrm{C}$ (a nonpermissive temperature which induces paralysis) for $6 \mathrm{~h}$ before injury; $\boldsymbol{A C}$, shifted to $37^{\circ} \mathrm{C}$ for 5 min during injury (see Materials and Methods), $\boldsymbol{A d}$, shifted to $37^{\circ} \mathrm{C}$ for the first $6 \mathrm{~h}$ after injury, or $\boldsymbol{A e}$, shifted to $37^{\circ} \mathrm{C}$ for hours $6-12$ after injury. For all conditions, animals were dissected and processed for visualization at $12 \mathrm{~h}$ after injury. $\boldsymbol{B}$, Representative images for indicated conditions and genotypes. The axons, labeled by expression of UAS-mCD8::GFP with the $\mathrm{m} 12$-Gal 4 driver, remained intact in para ${ }^{\text {ts } 1}$ mutants shifted for $6 \mathrm{~h}$ after injury (condition d). Scale bar, $100 \mu \mathrm{m}$. C, Quantification of the axon degeneration index for all conditions. The extent of axonal degeneration at different time points after injury was quantified by scoring the axon degeneration index for $\geq 20$ axons for each genotype, as described in Materials and Methods. Error bars represent SEM. ${ }^{* * *} p<0.001$, based on one-way ANOVA with Tukey's post hoc test.

trast, shifting to the nonpermissive temperature during the first $6 \mathrm{~h}$ after injury (Condition d in Fig. $2 A d$ ) significantly delayed axonal degeneration. Control animals subjected to this paradigm showed $\sim 80 \%$ axonal degeneration by $12 \mathrm{~h}$ after injury. In contrast, in para mutant animals $<5 \%$ of the axons had degenerated at $12 \mathrm{~h}$ (Fig. 2C). The degeneration of the NMJ synapse was similarly delayed (Fig. 3). The axons of para mutant larvae treated with condition $\mathrm{d}$ remained intact $16 \mathrm{~h}$ after the injury, but showed signs of partial degeneration at $22 \mathrm{~h}$ after the injury, and had completely degenerated $30 \mathrm{~h}$ after the injury (Fig. $4 A, B$ ). We observed similar results with a different allele of para, para ${ }^{\text {ST76 }}$ (Fig. 3). These observations suggested that sodium channel function affects degeneration events after injury, which presumably occur in the distal stump independently of the cell body.

To further determine the timing for the effect of the para mutations upon degeneration, we reduced the time of the temperature shift after injury. A temperature shift of para $^{\text {ts1 }}$ for only $1 \mathrm{~h}$ immediately after the injury was sufficient to confer partial protection against axonal degeneration, however a $1 \mathrm{~h}$ shift initiated $3 \mathrm{~h}$ after injury had only a mild effect upon degeneration (Fig. 4C,D). We conclude that an aspect of neuronal physiology that is influenced by the para subunit of voltage gated sodium channels plays an important role in the initiation of axonal degeneration in Drosophila motoneurons.

\section{Electrophysiology of NMJ synapses after injury}

The finding that silencing via the temperature shift in para mutants after injury inhibited axonal degeneration was puzzling. Previous studies in other systems suggested that it was unlikely that the distal stump would initiate action potentials on its own (Birks et al., 1960; Miledi and Slater, 1970; Tsao et al., 1999) but to directly address this possibility, we made intracellular recordings from muscle 6 in wild-type larvae. When the acutely cut nerve ( 0 h after cut) was drawn into a suction electrode and stimulated with pulses of increasing intensity, the pattern of postsynaptic responses indicated that two axons could be recruited. The lower threshold axon typically produced responses of $2-6 \mathrm{mV}($ mean $=2.4 \pm 0.9$ $\mathrm{mV}$ ) and the sum of both axons produced a response of $10-35 \mathrm{mV}$ (mean $=17 \pm$ $6.8 \mathrm{mV}$; Fig. $5 A, B$ ). From this it can be inferred that the higher threshold axon on its own, ignoring any nonlinear summation, would be expected to produce a response of 8-29 $\mathrm{mV}$. Responses to stimulating both axons could still be evoked $3 \mathrm{~h}$ after a crush, but no evoked EJPs were observed $6 \mathrm{~h}$ after a crush. This loss of synaptic function occurred earlier than the loss of axonal or NMJ continuity (Fig. 1; Xiong and Collins, 2012). Figures 1 and 5 show degeneration phenotypes for different motoneurons, but we observed that all motoneurons and NMJs degenerated with a similar rate. Moreover, the para mutations inhibited the loss of synaptic function from all injured NMJs (data not shown).

Spontaneous EJPs recorded from muscles connected to intact (uninjured) nerves (Fig. 5C,D) included many large events (5-35 $\mathrm{mV})$ as well as much more frequent small events $(0.25-5 \mathrm{mV})$. Based on the similarity of the amplitudes of the large events to the three size classes of EJPs revealed by nerve stimulation (axon 1 only, axon 2 only, and both axons), we conclude that these large events were the result of spikes initiated in the intact CNS. Once the nerve had been cut or crushed, only small spontaneous events (mean $=0.0 .84 \mathrm{mV}$ at $0 \mathrm{~h}$ ) were observed. From the absence of any spontaneous large events at times we demonstrated that stimulation could still produce them, we conclude that neither of the two distal axon stumps fired spontaneous action potentials.

The amplitude of the spontaneous miniature potentials was unchanged in the first $6 \mathrm{~h}$ after a nerve crush, but their frequency declined dramatically by $3 \mathrm{~h}$ and even further by $6 \mathrm{~h}$. Neither the amplitude nor the frequency of the small spontaneous EJPs observed immediately after a nerve crush were altered by TTX treatment, which also supports the conclusion that none of these 

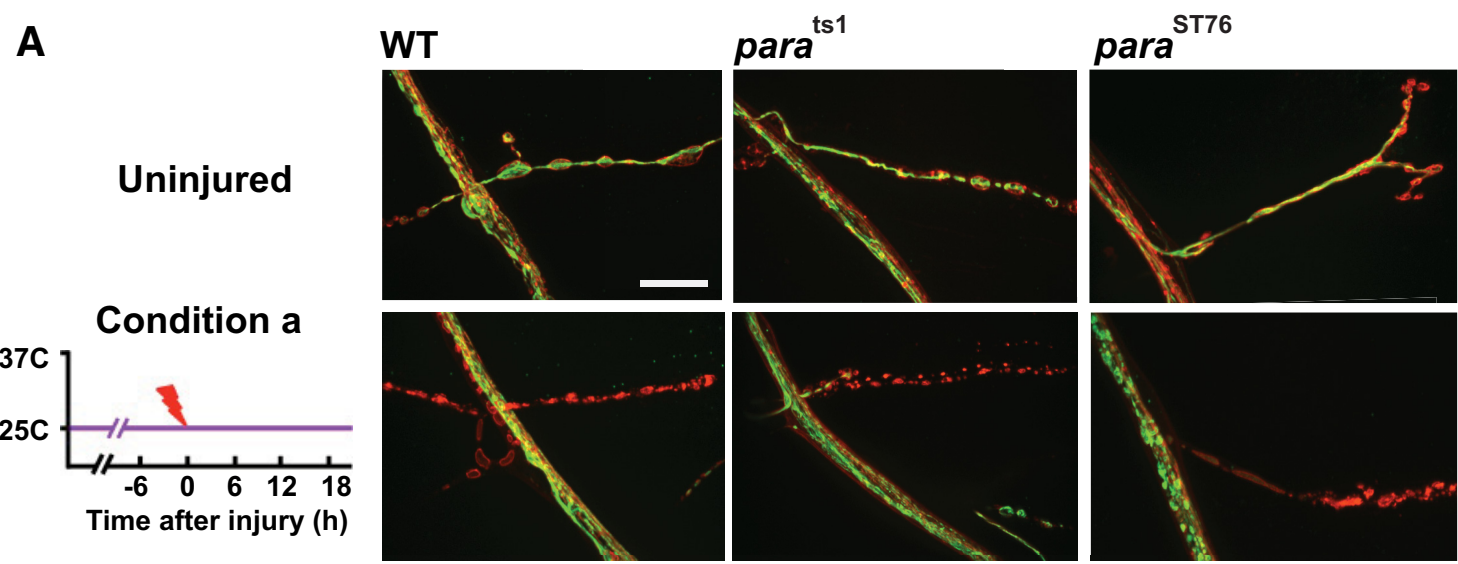

\section{Condition d}
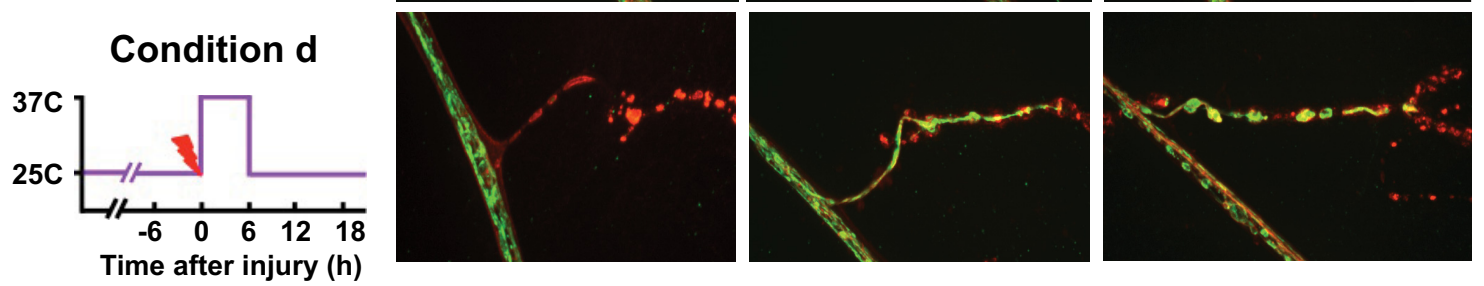

B

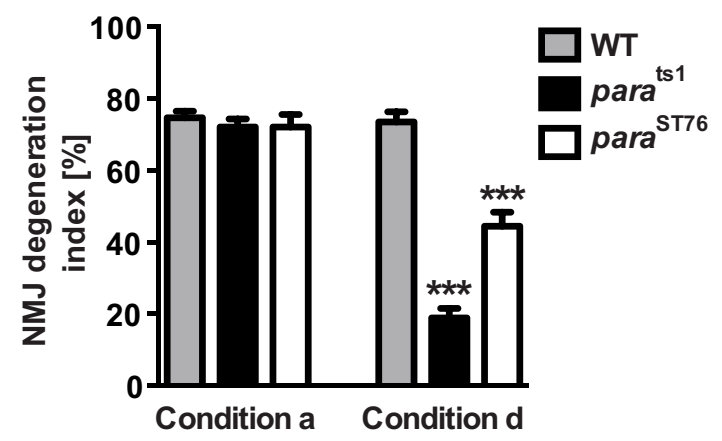

Figure 3. Acute silencing after injury delays synaptic degeneration. $\boldsymbol{A}$, Representative images from muscle 4 NMJs in wild-type (WT), para ${ }^{\text {ts } 1}$, and para ${ }^{\text {ST76 }}$ mutants $16 \mathrm{~h}$ after injury, treated according to the indicated conditions. In WT animals, in either Condition a or d, the presynaptic marker Futsch (green) completely disappeared, whereas the neuronal membrane, labeled with anti-HRP (red) remained in discontinuous fragments. In contrast, NMJs in both para ${ }^{\mathrm{ts} 1}$ and para ${ }^{\mathrm{ST} 76}$ mutants remain continuous and intact when shifted to $37^{\circ} \mathrm{C}$ for $6 \mathrm{~h}$ after injury. $\boldsymbol{B}, \mathrm{Quantification}$ of the NMJ degeneration index (see Materials and Methods) shows that both alleles of para protect synapses from degeneration when shifted for $6 \mathrm{~h}$ after injury; $n \geq 20 \mathrm{NMJ}$ for each genotype. Scale bar, $100 \mu \mathrm{m}$. Error bars represent SEM. ${ }^{* * *} p<0.001$, based on one-way ANOVA with Tukey's post hoc test.

events were the consequence of action potentials in the distal stumps.

An ex vivo assay for axonal degeneration reveals no effect for sodium channel blockade

Our inability to detect action potentials in the distal stump raised the question of what function voltage-gated sodium channels might play in regulating axonal degeneration. To probe this question, we used an "ex vivo" method (see Materials and Methods) that gave sufficient access to the axons to use pharmacological reagents. Even with HL3 solution exchanged for the hemolymph and most of the organs of the body removed, the changes in the axons were quite similar to that observed in vivo after a crush. Within $20 \mathrm{~h}$ of incubation, axonal sprouting was observed in the proximal stumps, whereas distal stumps and NMJs became extensively fragmented (Fig. 6A). Uninjured axons and synapses remained intact, and no evidence of apoptosis was observed. $\mathrm{Mu}-$ tations that inhibit axonal and synaptic degeneration in vivo, including the WldS mutation (Coleman and Freeman, 2010; Xiong and Collins, 2012), and expression of Kir2.1, dramatically inhib- ited degeneration in the ex vivo assay (Fig. 6B). Likewise, expression of SDN accelerated the rate of degeneration, and shifting of the para mutants within the first $6 \mathrm{~h}$ after injury delayed degeneration (Fig. 6C). These observations suggest that axonal and synaptic degeneration in this ex vivo preparation involves the same cellular events that take place in vivo.

In contrast to the genetic manipulations of sodium channels, application of TTX in the ex vivo assay did not alter the rate of axonal and synaptic degeneration (Fig. 6D,E). This is not because the TTX could not reach the axonal sodium channels, since the TTX application successfully blocked evoked EJPs (Fig. 5A,B), even after a $20 \mathrm{~h}$ incubation in HL3. This observation supports the interpretation that sodium channels do not regulate degeneration by driving action potentials in the distal stump.

Reduction in levels of the para sodium channel confers temperature-sensitive resistance to degeneration

The observation that mutations in para can protect axons from degeneration suggests that sodium channel function is indeed involved in some way in regulating degeneration. This function 
A

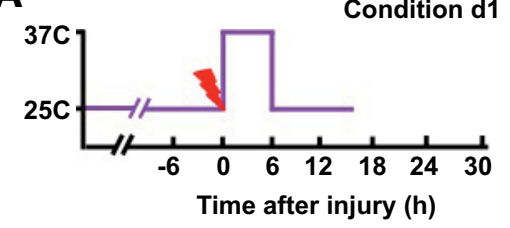

Condition d2

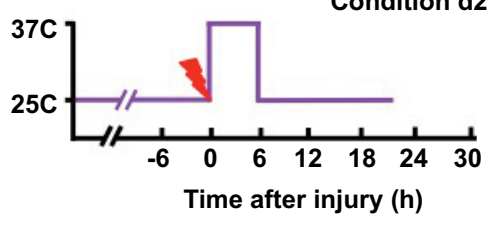

Condition d3

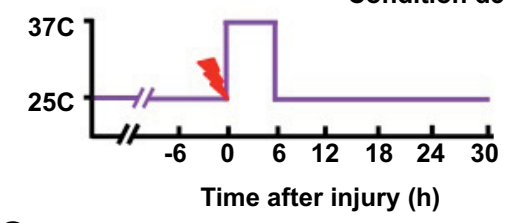

C
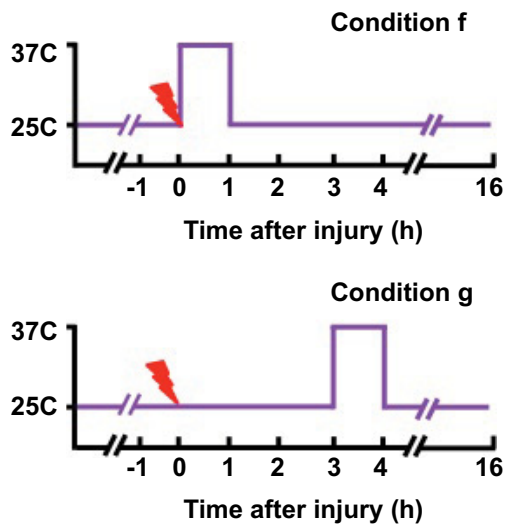

B

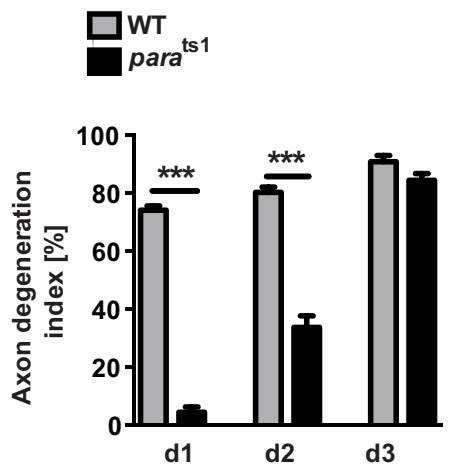

D

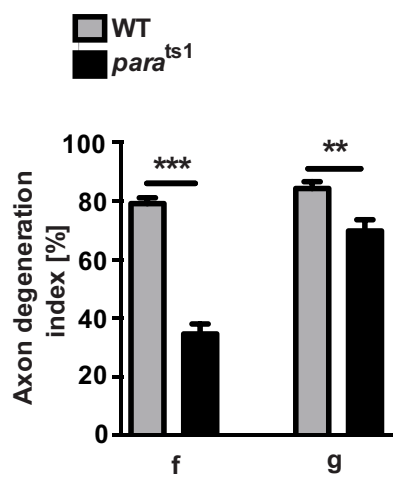

result from elevated temperature, so threshold cannot be achieved (Nelson and Wyman, 1990). A similar temperaturesensitive paralytic phenotype occurs in nap ${ }^{t s}$ mutants, which is thought to function by reducing the levels of Para protein (Kauvar, 1982; Stern et al., 1990).

To explore this idea further, we tested whether reduced levels of wild-type para mRNA could cause a temperature-dependent resistance to axonal degeneration. The Gal4/UAS system was used to express double-stranded interfering RNAi transgenes that target para mRNA in either $\mathrm{m} 12-\mathrm{Gal} 4$ expressing neurons or in all motoneurons. Strikingly, this manipulation resulted in a temperature-dependent inhibition of axonal and synaptic degeneration, similar to that of the para ${ }^{t s}$ alleles (Fig. $7 A, B)$. Furthermore, although TTX had no effect on the rate of degeneration in wildtype larvae studied in ex vivo preparations at normal temperature (Fig. 6D,E), TTX was partially protective when the temperature of wild-type larvae was elevated to $37^{\circ} \mathrm{C} \mathrm{imme-}$ diately after injury (Fig. 7C).

Previous studies have shown that the paralytic phenotype of para mutants depends upon $\mathrm{K}^{+}$channel function, because the $\mathrm{K}^{+}$channel inhibitor 4-AP can rescue the temperature-sensitive paralysis (Nelson and Wyman, 1990). We found that 4-AP can similarly rescue the temperaturedependent protection from degeneration in the para mutants (Fig. $7 D$ ). The protective effect of para mutations therefore depends upon $\mathrm{K}^{+}$channel function. Because action potentials do not appear to take place in the distal stump, these effects are unlikely to involve nerve excitability per se; rather, they may involve changes in the resting membrane potential.

\section{para mutants influence intra-axonal $\mathrm{Ca}^{2+}$ levels}

In studies of mammalian cultured neurons a critical event in Wallerian degeneration is a rise in intracellular calcium

could potentially reflect an action of sodium channels that are insensitive to TTX (possibly via an as yet uncharacterized isoform of para). However, the more likely explanation is that Para-containing sodium channels influence axonal degeneration via an indirect mechanism. To test this possibility, we altered sodium channel expression using a different approach.

For many temperature-sensitive mutations, the molecular action of the protein becomes inactivated specifically upon the shift to a higher temperature. However, an alternative mechanism, which has been suggested for para mutants, is that the mutation leads to lowered expression of sodium channels that function normally at both normal and elevated channels. (Loughney et al., 1989; O'Dowd et al., 1989). The failure to generate action potentials at high temperatures is attributed to having too few sodium channels to overcome the more rapid activation of potassium currents that also levels. Degeneration can be delayed by reducing extracellular $\left[\mathrm{Ca}^{2+}\right]$ for cultured neurons (Schlaepfer and Bunge, 1973; George et al., 1995). Conversely, increasing intracellular $\left[\mathrm{Ca}^{2+}\right]$ with calcium ionophores induces degeneration and overcomes the protective effect of the WldS mutation (Glass et al., 1994; George et al., 1995). We therefore hypothesized that the $\mathrm{Na}^{+}$and $\mathrm{K}^{+}$currents of axons may influence axonal degeneration by influencing $\mathrm{Ca}^{2+}$ entry.

We first confirmed that extracellular $\left[\mathrm{Ca}^{2+}\right]$ influences axonal degeneration in Drosophila motoneuron axons, using the $\mathrm{ex}$ vivo assay, by observing the extent of degeneration $20 \mathrm{~h}$ after a nerve crush. When animals were dissected and placed into culture with HL3 containing $0 \mathrm{~mm} \mathrm{CaCl}_{2}$ and 1 mM EGTA within 15 min after the nerve crush injury and maintained in this $0 \mathrm{Ca}^{2+}$ media for the rest of incubation, degeneration was dramatically 
inhibited (Fig. 8A, Condition B). Holding calcium low for shorter periods of time (the first $3 \mathrm{~h}$, the first $6 \mathrm{~h}$, or hours $6-20$ ) also produced a significant, albeit more modest, inhibition of degeneration (Fig. 8A, Conditions C-E). Extracellular $\left[\mathrm{Ca}^{2+}\right]$ is therefore important throughout the lag period between injury and the onset of axonal degeneration, including the first $3 \mathrm{~h}$ after injury when the para $^{\text {ts }}$ shift is most effective.

If the $\mathrm{Na}^{+}$and $\mathrm{K}^{+}$channel currents influence axonal degeneration by promoting $\mathrm{Ca}^{2+}$ entry, then the protective effect of reducing extracellular $\left[\mathrm{Ca}^{2+}\right]$ should be epistatic to the para and SDN mutations. Indeed, the temperature shifted para animals, when incubated in $0 \mathrm{~mm}$ $\left[\mathrm{Ca}^{2+}\right]$, showed a similar degree of axonal degeneration to $\mathrm{WT}$ animals incubated in 0 $\mathrm{mm}\left[\mathrm{Ca}^{2+}\right.$ ] (Fig. $8 B$ ). Hence, the protective effects of $0 \mathrm{~mm}\left[\mathrm{Ca}^{2+}\right]$ and the para mutation are not additive. Incubation in $0 \mathrm{~mm}$ $\left[\mathrm{Ca}^{2+}\right]$ also inhibited the prodegenerative effect of SDN mutations (Fig. 8C). The epistasis of extracellular $\left[\mathrm{Ca}^{2+}\right]$ supports the model that the $\mathrm{Na}^{+}$and $\mathrm{K}^{+}$mutations influence axonal degeneration by influencing the entry of $\mathrm{Ca}^{2+}$ into the axon.

To study the dynamics of intra-axonal calcium during degeneration, we measured the fluorescence of the genetically encoded $\mathrm{Ca}^{2+}$ reporter, GCaMP 3.0 (Tian et al., 2009), which was expressed in motoneurons using the pan-motoneuron driver OK6-Gal4. Figure $8 D$ shows the mean GCaMP 3.0 intensity measurements made from five nerves in two uninjured larvae and from 24 nerves in 14 injured larvae, at time points after injury ranging from $15 \mathrm{~min}$ to $9.5 \mathrm{~h}$. The GCaMP intensity of uninjured axons was assigned a relative value of 1 , and the intensity of this signal did not change significantly during $3 \mathrm{~h}$ of observation. In contrast, from the first time that the calcium signal from injured axons could be measured (15 min after injury) GCaMP intensity was significantly elevated (Fig. $8 D, E$ ). This rise in intracellular $\left[\mathrm{Ca}^{2+}\right]$ depended upon extracellular $\left[\mathrm{Ca}^{2+}\right]$, because it was abolished by placing the preparation into HL3 containing $0 \mathrm{~mm}$ calcium (Fig. $8 E$ ). The increase in GCaMP 3.0 signal persisted for $\sim 4 \mathrm{~h}$ (Fig. $8 D$ ), which is consistent with the $3 \mathrm{~h}$ period after injury that we found was particularly sensitive to para manipulations. We had no way of determining whether degradation of GCaMP 3.0 also contributed to the decline in the intensity of the signal, but because the signal intensity gradually rose between 6 and $10 \mathrm{~h}$ after injury (consistent with a second rise in axonal $\left[\mathrm{Ca}^{2+}\right]$ as axons begin to degenerate) considerable GCaMP 3.0 must have been present over the entire time period

A

E
B
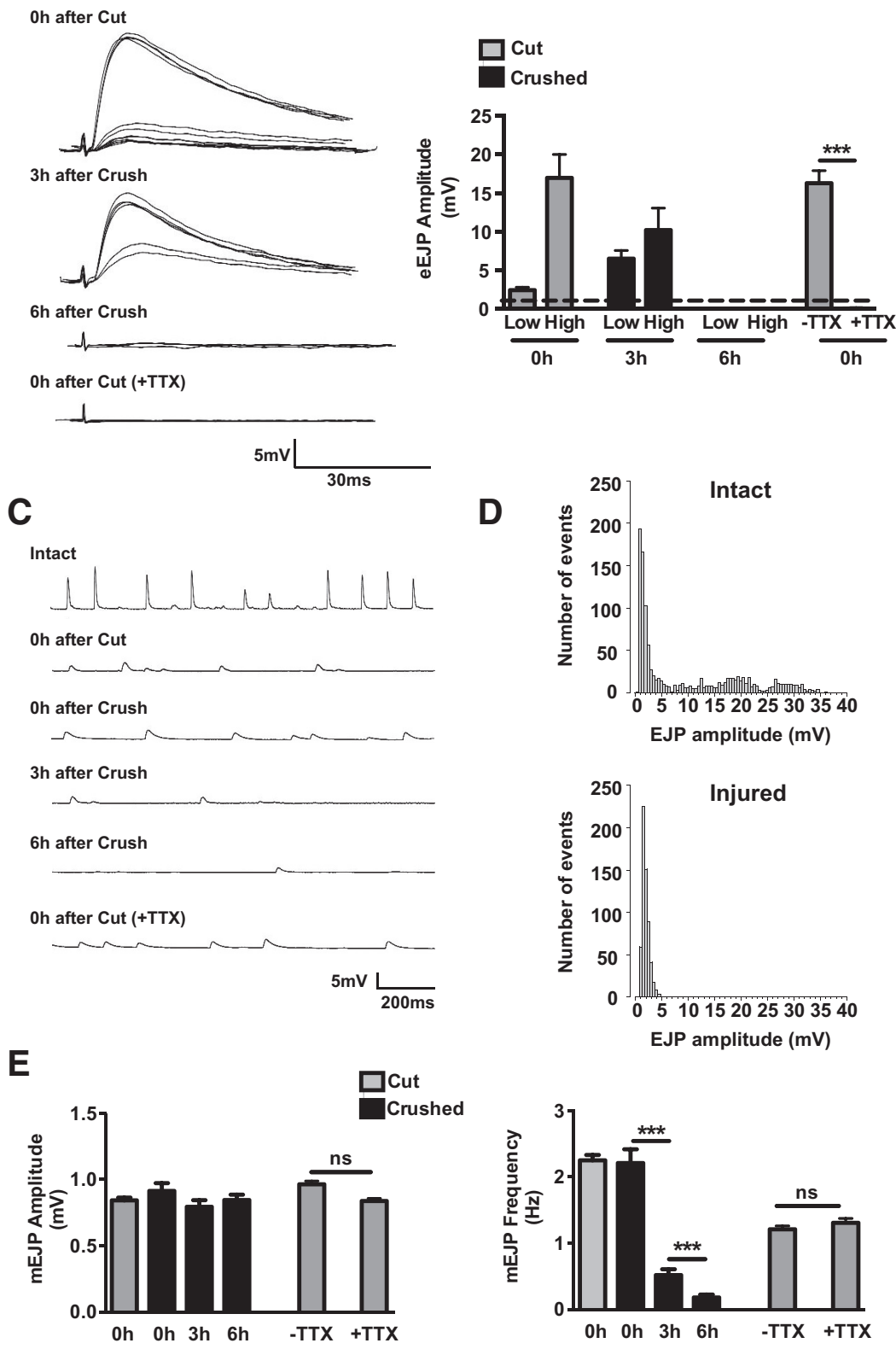

D
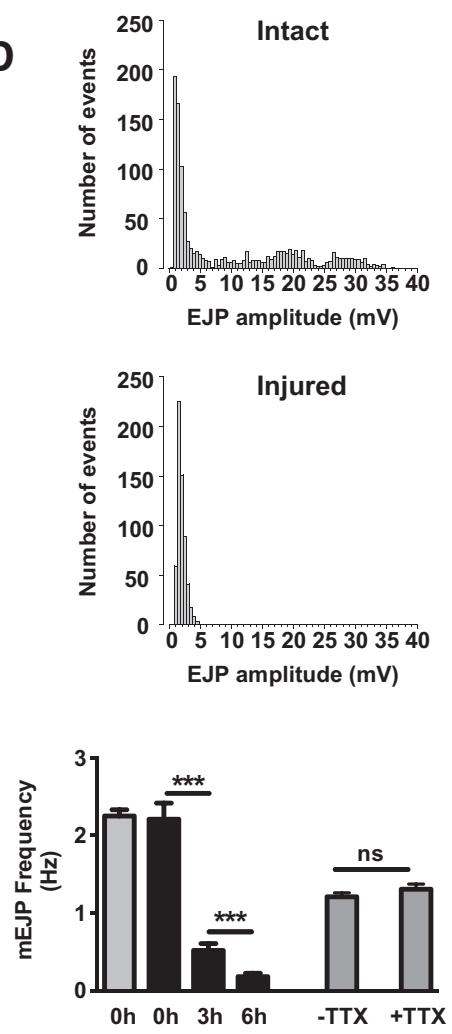

Figure 5. Electrophysiology of injured NMJ synapses on muscle 6 of wild-type (Canton S) larvae. $A$, Representative traces from evoked EJP recordings, conducted either 0,3 , or $6 \mathrm{~h}$ after injury, or in the presence of $1 \mu \mathrm{m}$ TTX. Because muscle 6 in innervated by two neurons, we gradually increased the amplitude of the stimulation to sequentially recruit the two axons. Representative events from the axon with a lower stimulation threshold are shown superimposed with larger events reached by stimulation of both axons. B, Quantification of mean evoked EJP amplitudes for the low stimulus threshold axon (low) and the combined axons (high stiumulus) at muscle 6. Evoked EJPs could not be detected $6 \mathrm{~h}$ after injury or in the presence of TTX immediately after injury. The dotted line indicates the mean amplitude of the spontaneous mEJP events. C, Representative recordings made from muscle 6 , which show spontaneous activity from intact (top row) or injured (bottom five rows) segmental nerves. For the "cut" injury, animals were prepared according to the standard paradigm of cutting the nerves immediately after dissection before recording (Zhang and Stewart, 2010). For the "crush" injuries, animals were dissected in HL3 solution either $0 \mathrm{~h} \mathrm{(} 2 \mathrm{~min}$ ), 3 or $6 \mathrm{~h}$ after the nerve crush. $\boldsymbol{D}$, Distribution of spontaneous EJPs measured at muscle 6 when nerves were intact (uninjured), or injured (cut) immediately before recording. Data were derived from three intact preparations and 10 injured preparations. $E$, Quantification of mean $\mathrm{mEJP}$ amplitudes and frequencies recorded from the different conditions. There is no difference in $\mathrm{mEJPs}$ from crushed or cut nerves. In animals dissected $3-6 \mathrm{~h}$ after nerve crush, there was a significant decrease in mEJP frequency. Supporting the interpretation that all of the spontaneous events recorded were minis, we detected no change in the presence of TTX; $n=10$ recordings (NMJs) for each condition. Error bars represent SEM. ${ }^{* * *} p<0.001$, based on one-way ANOVA with Tukey's post hoc test.

measured. These observations are consistent with other studies that have measured a rise in calcium during the lag phase between the actual injury and the initiation of degeneration (Mata et al., 1986; LoPachin et al., 1990; Adalbert et al., 2012). 

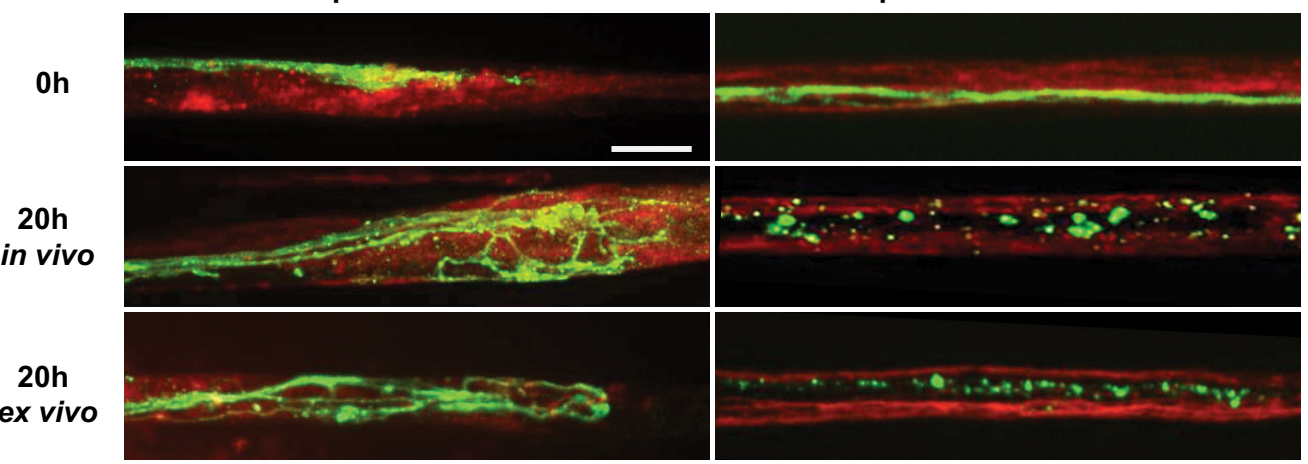

B

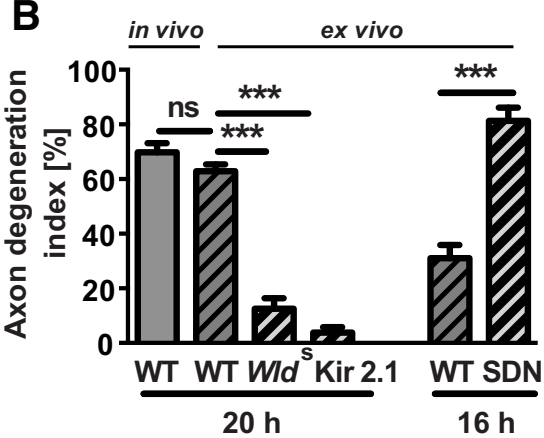

C

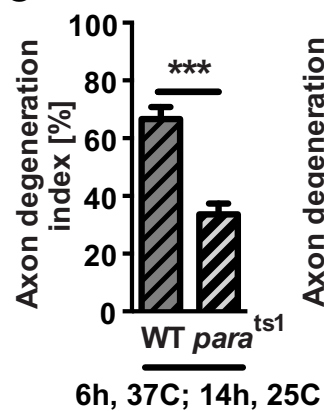

D

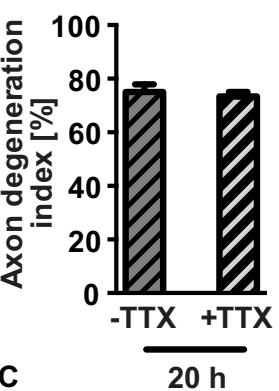

E

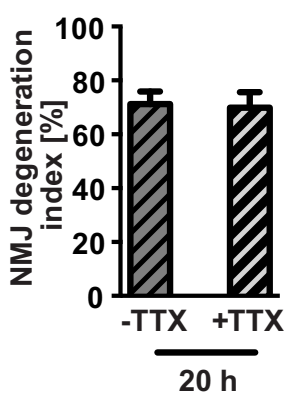

Figure 6. Ex vivo study revealed no effects of TTX on axonal or synaptic degeneration at room temperature. $A$, The Gal4/UAS system was used to express UAS transgenes specifically in two fasiculated motoenurons similarly to Figure $1 . \boldsymbol{A}$, Examples of proximal and distal stumps at $20 \mathrm{~h}$ after injury from ex vivo and in vivo preparations. $\boldsymbol{B}-\boldsymbol{E}$, The extent of axonal degeneration at different time points after injury was quantified by scoring the axon degeneration index as described in Materials and Methods. Hatched bars indicate experiments using the ex vivo assay; $n \geq 20$ axons for each condition and genotype. Genotypes used: WT [m12-Gal4, UAS-mCD8::GFP/+ (Canton S background)], WId [m12-Gal4, UAS-mCD8::GFP/UAS-WId5], Kir2.1 [m12-Gal4, UAS-mCD8::GFP/UAS-Kir2.1], SDN [m12-Gal4, UAS-mCD8::GFP/UAS-SDN] and para ${ }^{\text {ts1 }}$ [para ${ }^{\text {ts1 }} / \mathrm{Y}$; m12-Gal4, UAS-mCD8::GFP/+]. C, Animals were shifted to $37^{\circ} \mathrm{C}$ for $6 \mathrm{~h}$ after injury, then brought back to $25^{\circ} \mathrm{C}$ for $14 \mathrm{~h}$ before dissection. Axons in the para mutant were protected from degeneration similarly at comparable time points in vivo (Fig. $4 A$ ). $\boldsymbol{D}, \boldsymbol{E}, \mathrm{Quantification}$ showing axonal and NMJ degeneration index from wild-type larvae in the absence or presence of $1 \mu \mathrm{M}$ TTX. TTX did not affect of the extent of axonal or synaptic degeneration. Error bars represent SEM. ${ }^{* * *} p<0.001$, based on one-way ANOVA with Tukey's post hoc test.

If the para mutations inhibit $\mathrm{Ca}^{2+}$ entry, then they should inhibit the increase in intra-axonal $\left[\mathrm{Ca}^{2+}\right]$ after injury. The baseline GCaMP 3.0 intensity in uninjured axons was elevated in para mutant animals compared with control, but it was striking that we observed no significant increase in GCaMP 3.0 intensity after injury (Fig. $8 F$ ). Conversely, the SDN mutations that accelerated degeneration caused an increase in GCaMP 3.0 intensity similar to wild-type at $15 \mathrm{~min}$, but the calcium level at $3 \mathrm{~h}$ postinjury was significantly elevated above controls (Fig. 8G). These findings suggest that manipulating the $\mathrm{Na}^{+}$or $\mathrm{K}^{+}$channels regulate axonal degeneration by influencing the entry of $\mathrm{Ca}^{2+}$ into the distal axon.

\section{Discussion}

$\mathrm{Na}^{+}$and $\mathrm{K}^{+}$currents in distal axons influence

Wallerian degeneration

Wallerian degeneration of injured axons appears to be an active process, and recent studies have identified a number of molecules whose function is required for Wallerian degeneration to procede (for review, see Wang et al., 2012). However, less attention has been paid to the electrical and synaptic activities of axons, which also change dramatically after injury (Birks et al., 1960; Hunt and Nelson, 1965; Miledi and Slater, 1970; Moldovan et al., 2009). We have considered whether such changes can influence the process of Wallerian degeneration. Using a Drosophila injury model to study the degeneration of motoneuron axons in vivo, our findings indicate that the channels that regulate neuronal excitability make an important contribution to regulating the Wallerian degeneration process.

Although injury itself can induce action potentials in the distal stump (Ambron and Walters, 1996; Abegg, 2007), our conditional silencing experiments at different time points suggest that any action potentials at the time of injury do not affect the degeneration process. Instead, shifting para mutations to the nonpermissive temperature within the first several hours after injury inhibited axonal and synaptic degeneration. This was perplexing, because the distal stump of an injured axon was not expected to initiate action potentials. Indeed, our electrophysiological recordings at the larval NMJ revealed no evidence for such action potentials in injured motoneurons. Moreover, application of TTX, at concentrations that silence action potentials, did not affect the rate of axonal degeneration. We interpret this to mean that $\mathrm{Na}^{+}$and $\mathrm{K}^{+}$channels influence degeneration independently of the presence of spikes.

$\mathrm{Ca}^{2+}$ influx during the lag phase after injury promotes axonal degeneration

A key event in the degeneration of injured axons in mammals is the entry of $\mathrm{Ca}^{2+}$ through plasma membrane channels, because reducing extracellular calcium or adding calcium channel inhibitors to injured axons can inhibit degeneration (Schlaepfer and Bunge, 1973; George et al., 1995). Although the injury itself induces an acute rise in intra-axonal $\mathrm{Ca}^{2+}$ (Ziv and Spira, 1993; Knöferle et al., 2010; Avery et al., 2012), this increase is short- 
lived as the membrane reseals ( $\mathrm{Ziv}$ and Spira, 1995; Eddleman et al., 1998). Although this spike is important for acute axonal degeneration close to the injury site (Knöferle et al., 2010), its role in the Wallerian degeneration of axonal segments distant to the injury has been debated (George et al., 1995; Adalbert et al., 2012), due to the long lag phase between the initial $\mathrm{Ca}^{2+}$ spike and initiation of degeneration. Our present study has provided further investigation of this lag phase, both through timing-of-action experiments and in vivo $\mathrm{Ca}^{2+}$ imaging over long time frames. Our results support the model that $\mathrm{Ca}^{2+}$ influx during the lag phase after injury promotes degeneration. During this time frame, the para mutations are protective when shifted to the nonpermissive temperature, and intraaxonal $\left[\mathrm{Ca}^{2+}\right]$ becomes elevated in distal axons. This elevation depends upon extracellular $\left[\mathrm{Ca}^{2+}\right]$ (hence reflects $\mathrm{Ca}^{2+}$ entry) and is influenced by the para and SDN mutations.

\section{Interaction between sodium and potassium currents and calcium signaling}

If intracellular free calcium is the key regulator, then the ability of changes in the activity of $\mathrm{Na}^{+}$channels and $\mathrm{K}^{+}$channels to alter the extent of degeneration could be readily explained. One possibility is that there are changes in resting membrane potential of the distal axonal membrane by enhanced opening or closing of endogenous channels. Alternatively, changes in intracellular ion concentration might change the current flowing through the same constellation of open channels. Either change would influence the probability of $\mathrm{Ca}^{2+}$ influx through voltage gated $\mathrm{Ca}^{2+}$ channels. Changes in the excitability of injured distal axons have been previously inferred through electrophysiological studies (Moldovan et al., 2009). $\mathrm{x}$-ray microprobe analysis of elemental distributions in injured sciatic nerves have also noted changes in the levels of axonal $\mathrm{K}$ and $\mathrm{N}$, which precede changes in Ca (LoPachin et al., 1990).

If the initial effect of injury is a slight depolarization from the normal resting potential, this depolarization would bring the membrane potential into a range where voltage-gated $\mathrm{Ca}^{2+}$ channels can open and further depolarize the membrane. However, if $\mathrm{Na}^{+}$channels are too few to elicit spontaneous action potentials, the membrane potential would stabilize at a depolarized level. In this potential range, $\mathrm{Ca}^{2+}$ channels could repeatedly open and close without becoming trapped in the inactivated state, and a standing $\mathrm{Ca}^{2+}$ current would be produced. The protective (Kir2.1) and prodegenerative $(\mathrm{SDN}) \mathrm{K}^{+}$channel manipulations would act by making the final membrane potential more negative or more positive respectively, thus modulating the amplitude of the calcium conductance.

The action of the para mutant is more complex. Although the mutant paralysis phenotype is only manifest at elevated temper-
B
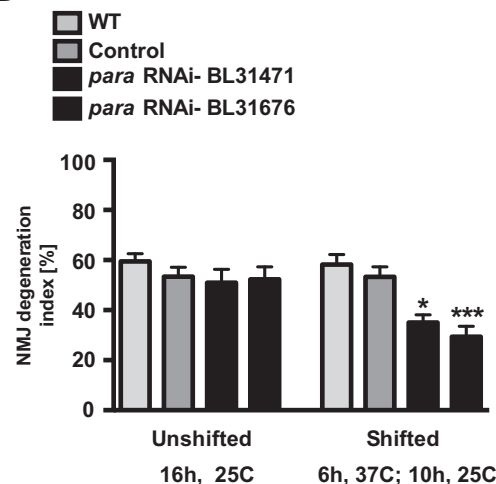

$6 \mathrm{~h}, 37 \mathrm{C} ; 10 \mathrm{~h}, 25 \mathrm{C}$

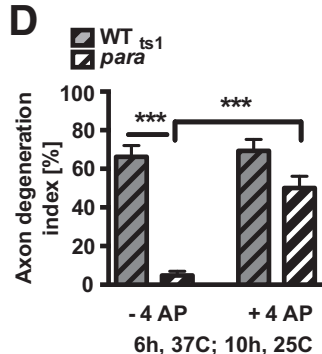

$16 \mathrm{~h}, 25 \mathrm{C}$

Figure 7. A reduction of para transcript conferred temperature-sensitive resistance to degeneration. $\boldsymbol{A}$, The axon degeneration (ren were subjected to the same injury and temperature-shift protocol. $C$, The axonal degeneration index was quantified for m12-Gal4-

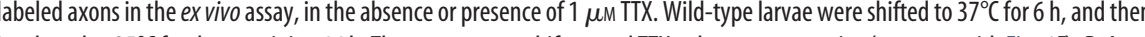

ature, the molecular defect (a decreased expression of channels with normal function) is already present at normal temperature (Loughney et al., 1989; O'Dowd et al., 1989). At elevated temperature the mutation is paralytic because there is more rapid activation of $\mathrm{K}^{+}$currents, and the reduced number of $\mathrm{Na}^{+}$channels is unable to overcome the enhanced $\mathrm{K}^{+}$current and drive the cell past threshold (Nelson and Wyman, 1990). Our results suggest that at $25^{\circ} \mathrm{C}, \mathrm{Na}^{+}$channels have no role in regulating degeneration, as TTX has no effect on the process, and degeneration in the unshifted para mutants is no different from in wild-type larvae. In contrast, at elevated temperature, para mutations (and TTX) are protective. The likely explanation is that with normal levels of functional Para protein, the enhanced $\mathrm{K}^{+}$current at elevated temperature is countered by sufficient levels of $\mathrm{Na}^{+}$channel function. However, when Para protein levels are low (or $\mathrm{Na}^{+}$ channels are inhibited by TTX) the enhanced $\mathrm{K}^{+}$currents drive the cell to a potential too negative for $\mathrm{Ca}^{2+}$ influx, and hence degeneration is slowed.

It is of interest to compare Wallerian degeneration to axonal degeneration after other forms of injury, such anoxic and ischemic damage, and loss of myelination (for review, see zharv; 58Stys, 2005). In these other models, injured axons can still 
A
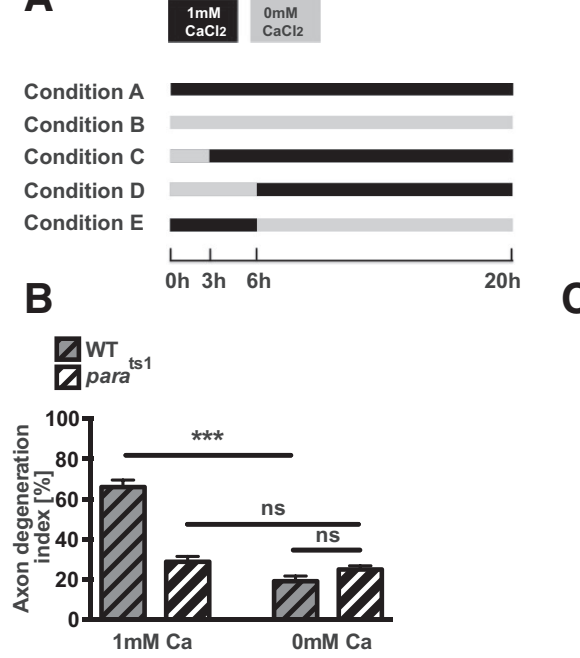

D

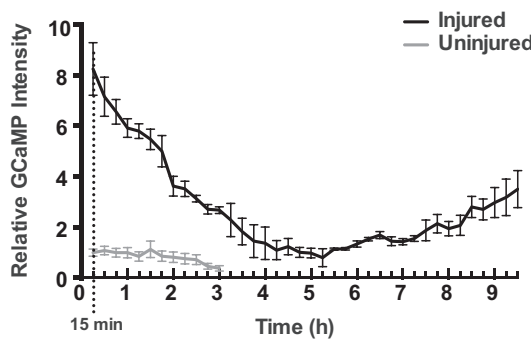

$\mathbf{F}$
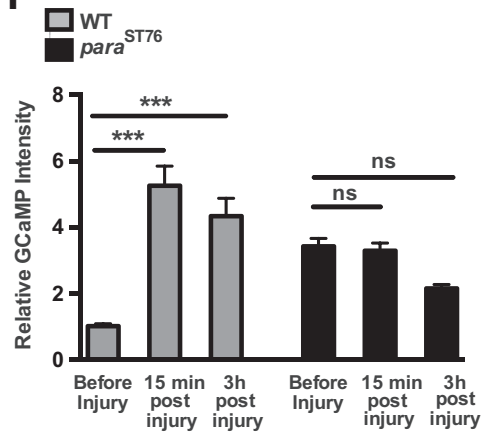

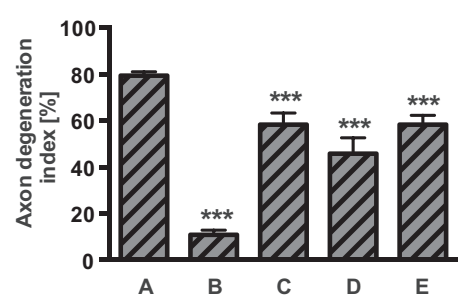

C

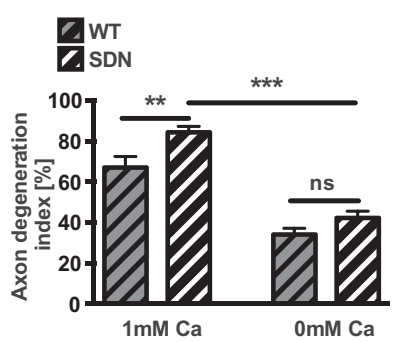

E

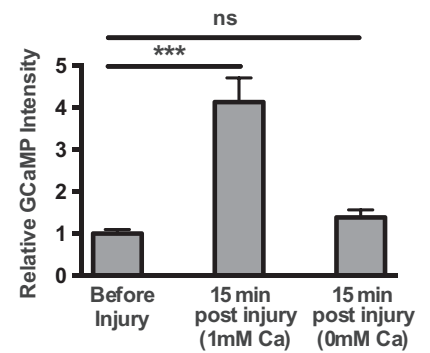

G
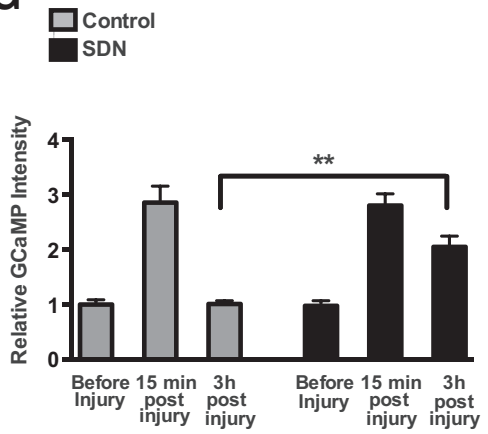

Figure 8. Calcium concentration changes in injured distal axons regulate degeneration. $A$, Effect of exposure to $0 \mathrm{~mm}$ $\mathrm{CaCl}_{2}$ (supplemented with $1 \mathrm{~mm}$ EGTA) at various times after injury. Left, The five conditions tested. Right, The axon degeneration index in the ex vivo assay quantified for $\mathrm{m} 12$-Gal4 UAS-mCD8:GFP-labeled neurons after incubation for $20 \mathrm{~h}$. $\boldsymbol{B}$, Protection by the para mutation is not enhanced by removal of extracellular $\mathrm{Ca}^{2+}$. WT [m12-Gal4, UAS-mCD8::GFP/+] and para ${ }^{\text {ts }}\left[\mathrm{para}^{\text {t5 }} ; \mathrm{m} 12-\mathrm{Gal} 4\right.$, UAS-mCD8::GFP/+ ] animals in the ex vivo assay were shifted in parallel to $37^{\circ} \mathrm{C}$ for $6 \mathrm{~h}$ after injury and then brought back to $25^{\circ} \mathrm{C}$ for the remaining $14 \mathrm{~h}$ before dissection. $C$, The acceleration of degeneration caused by SDN mutation is suppressed by removing extracellular $\mathrm{Ca}^{2+}$. WT [m12-Gal4, UAS-mCD8::GFP/+ ] ]and SDN [m12-Gal4, UAS-mCD8::GFP/UAS-SDN] animals were incubated in parallel for $16 \mathrm{~h}$ in $\mathrm{HL} 3$ containing either 1 or $0 \mathrm{~mm} \mathrm{CaCl}$. D, Time course of changes in axonal $\mathrm{Ca}^{2+}$, detected by GCaMP3.0 fluorescence in injured motoneuron axons. See Materials and Methods for details. The increase in fluorescence from injured axons ( $15 \mathrm{~min}$ after injury) varied slightly between experiments (from eightfold in $\boldsymbol{D}$ to fourfold in $\boldsymbol{E}$ and fivefold in $\boldsymbol{F}$ ). However in each case, the GCaMP intensity measured in different nerves and in different animals for the same experimental condition, was quite similar. $\boldsymbol{E}$, The increase in intra-axonal $\mathrm{Ca}^{2+}$ after injury required external $\mathrm{Ca}^{2+}$. Animals were dissected 15 min after injury and imaged in $\mathrm{HL} 3$ media containing either $1 \mathrm{~mm} \mathrm{CaCl}$ or $0 \mathrm{~mm} \mathrm{CaCl}$ (supplemented with $1 \mathrm{~mm}$ EGTA). GCaMP fluorescence intensity was normalized to uninjured axons imaged concurrently under identical conditions. $\boldsymbol{F}$, Para mutations inhibit increases in axonal $\mathrm{Ca}^{2+}$ after injury. GCaMP fluorescence was measured in WT [0K6-Gal4, UAS-GCaMP/+] or parats $\left[\right.$ para $^{\text {ST76; }}$ OK6-Gal4, UAS-GCaMP/+] larvae as described above. Animals were raised at $25^{\circ} \mathrm{C}$ and shifted to $37^{\circ} \mathrm{C}$ immediately after injury. G, Intra-axonal $\mathrm{Ca}^{2+}$ was enhanced at $3 \mathrm{~h}$ after injury in SDN mutants (OK6-Gal4, UAS-GCaMP3.0/+; UAS-SDN) compared with control animals containing the same number of UAS-transgenes (OK6-Gal4, UAS-GCamp3.0/+; UASmoody-RNAi); $n \geq 15$ nerves for all experiments. ${ }^{* *} p<0.01,{ }^{* * *} p<0.001$, based on one-way ANOVA with Tukey's post hoc test. experiences action potentials, and $\mathrm{Na}^{+}$ channel inhibitors such as TTX are protective (Stys et al., 1992; Bechtold et al., 2005). In contrast, TTX does not inhibit Wallerian degeneration after acute injury (George et al., 1995; Press and Milbrandt, 2008; and this study), and action potentials do not appear to take place. An interesting similarity for all of these injury models, is that axonal degeneration can be inhibited by the WldS mutation (Gillingwater et al., 2004; Kaneko et al., 2006; Coleman and Freeman, 2010). A recent study suggests that the WldS mutation can prolong the ATP generating capacity of distal axons (Shen et al., 2013), which is important for the maintenance of the membrane potential via the $\mathrm{Na}^{+} / \mathrm{K}^{+}$exchanger, a major consumer of ATP in axons. The changes in elemental distribution during Wallerian degeneration are consistent with a run-down in $\mathrm{Na}^{+} / \mathrm{K}^{+}$ exchanger function (LoPachin et al., 1990), even though the absence of action potentials predicts a low demand for its activity. Because our study suggests that $\mathrm{Na}^{+}$and $\mathrm{K}^{+}$currents can influence degeneration even in the absence of action potentials, a rundown of $\mathrm{Na}^{+} / \mathrm{K}^{+}$exchanger function, which can be coupled to a rundown of mitochondrial function, may be relevant for Wallerian degeneration as well as other injury models. In this scenario, the WldS mutation might protect axons by inhibiting changes in membrane potential and subsequent $\mathrm{Ca}^{2+}$ influx.

\section{Conclusions}

In this study we have found that the degeneration of injured axons is strongly influenced by manipulating the excitability of the axonal membrane, even though injured axons do not initiate action potentials on their own. $\mathrm{Na}^{+}$and $\mathrm{K}^{+}$currents in distal axons most likely regulate degeneration by influencing the entry of external $\mathrm{Ca}^{2+}$ during the lag phase after injury.

Although this study has focused upon Drosophila motoneurons, para $^{t s}$ mutations are also protective for Drosophila sensory neurons (data not shown). Axonal degeneration takes place with different kinetics in different neuron types; however, the protection of all axons by mutations, such as WldS, suggests a universal underlying mechanism for axonal degeneration. $\mathrm{Na}^{+}$and $\mathrm{K}^{+}$ion permeabilities of axonal membranes are features that vary between individual cell types; hence, these differences may contribute to the unique kinetics of $\mathrm{Ca}^{2+}$ entry and degeneration in different cell types. 
Much remains to be learned about the mechanism of axonal degeneration, in particular the actions and relationships of recently identified molecular players in the process: Nmnat (Gilley and Coleman, 2010), Sarm (Osterloh et al., 2012), Hiw (Xiong et al., 2012; Babetto et al., 2013), and JNK (Miller et al., 2009; Barrientos et al., 2011). These factors may potentially influence degeneration upstream or in parallel to $\mathrm{Na}^{+}$and $\mathrm{K}^{+}$channels by influencing the permeability of the axonal membrane to $\mathrm{Ca}^{2+}$. Alternatively, some of these molecules may function in a signaling pathway that becomes stimulated by the $\mathrm{Ca}^{2+}$ influx. Our in vivo and ex vivo assays to study axonal degeneration in Drosophila motoneurons allow for a combination of genetic, electrophysiology, imaging, and pharmacology approaches to understand this intriguing pathway.

\section{References}

Abegg MH (2007) Rhythmic synaptic activity induced by mechanical injury of rat CA3 hippocampal area. J Neurotrauma 24:1536-1542. CrossRef Medline

Aberle H, Haghighi AP, Fetter RD, McCabe BD, Magãlhaes TR, Goodman CS (2002) Wishful thinking encodes a BMP type II receptor that regulates synaptic growth in Drosophila. Neuron 33:545-558. CrossRef Medline

Adalbert R, Morreale G, Paizs M, Conforti L, Walker SA, Roderick HL, Bootman MD, Siklós L, Coleman MP (2012) Intra-axonal calcium changes after axotomy in wild-type and slow Wallerian degeneration axons. Neuroscience 225:44-54.

Ambron RT, Walters ET (1996) Priming events and retrograde injury signals: a new perspective on the cellular and molecular biology of nerve regeneration. Mol Neurobiol 13:61-79. CrossRef Medline

Avery MA, Rooney TM, Pandya JD, Wishart TM, Gillingwater TH, Geddes JW, Sullivan PG, Freeman MR (2012) WldS prevents axon degeneration through increased mitochondrial flux and enhanced mitochondrial $\mathrm{Ca}^{2+}$ buffering. Curr Biol 22:596-600. CrossRef Medline

Babetto E, Beirowski B, Russler EV, Milbrandt J, DiAntonio A (2013) The Phr1 ubiquitin ligase promotes injury-induced axon self-destruction. Cell Rep 3:1422-1429. CrossRef Medline

Baines RA, Uhler JP, Thompson A, Sweeney ST, Bate M (2001) Altered electrical properties in Drosophila neurons developing without synaptic transmission. J Neurosci 21:1523-1531. Medline

Bainton RJ, Tsai LT, Schwabe T, DeSalvo M, Gaul U, Heberlein U (2005) moody encodes two GPCRs that regulate cocaine behaviors and bloodbrain barrier permeability in Drosophila. Cell 123:145-156. CrossRef Medline

Barrientos SA, Martinez NW, Yoo S, Jara JS, Zamorano S, Hetz C, Twiss JL, Alvarez J, Court FA (2011) Axonal degeneration is mediated by the mitochondrial permeability transition pore. J Neurosci 31:966-978. CrossRef Medline

Bechtold DA, Yue X, Evans RM, Davies M, Gregson NA, Smith KJ (2005) Axonal protection in experimental autoimmune neuritis by the sodium channel blocking agent flecainide. Brain 128:18-28. CrossRef Medline

Birks R, Katz B, Miledi R (1960) Physiological and structural changes at the amphibian myoneural junction, in the course of nerve degeneration. J Physiol 150:145-168. Medline

Bittner GD (1991) Long-term survival of anucleate axons and its implications for nerve regeneration. Trends Neurosci 14:188-193. CrossRef Medline

Budnik V, Gorczyca M, Prokop A (2006) Selected methods for the anatomical study of Drosophila embryonic and larval neuromuscular junctions. Int Rev Neurobiol 75:323-365. CrossRef Medline

Chaudhry V, Cornblath DR (1992) Wallerian degeneration in human nerves: serial electrophysiological studies. Muscle Nerve 15:687-693. CrossRef Medline

Coleman M (2005) Axon degeneration mechanisms: commonality amid diversity. Nat Rev Neurosci 6:889-898. CrossRef Medline

Coleman MP, Freeman MR (2010) Wallerian degeneration, wld(s), and nmnat. Annu Rev Neurosci 33:245-267. CrossRef Medline

Eddleman CS, Ballinger ML, Smyers ME, Fishman HM, Bittner GD (1998) Endocytotic formation of vesicles and other membranous structures induced by Ca2+ and axolemmal injury. J Neurosci 18:4029-4041. Medline
Ganetzky B, Wu CF (1982) Drosophila mutants with opposing effects on nerve excitability: genetic and spatial interactions in repetitive firing. J Neurophysiol 47:501-514. Medline

Ganetzky B, Wu CF (1983) Neurogenetic analysis of potassium currents in Drosophila: synergistic effects on neuromuscular transmission in double mutants. J Neurogenet 1:17-28. CrossRef Medline

Ganetzky B, Loughney K, Wu CF (1986) Analysis of mutations affecting sodium channels in Drosophila. Ann N Y Acad Sci 479:325-337. CrossRef Medline

George EB, Glass JD, Griffin JW (1995) Axotomy-induced axonal degeneration is mediated by calcium influx through ion-specific channels. J Neurosci 15:6445-6452. Medline

Gilley J, Coleman MP (2010) Endogenous Nmnat2 is an essential survival factor for maintenance of healthy axons. PLoS Biol 8:e1000300. CrossRef Medline

Gillingwater TH, Haley JE, Ribchester RR, Horsburgh K (2004) Neuroprotection after transient global cerebral ischemia in Wld(s) mutant mice. J Cereb Blood Flow Metab 24:62-66. CrossRef Medline

Glass JD, Schryer BL, Griffin JW (1994) Calcium-mediated degeneration of the axonal cytoskeleton in the Ola mouse. J Neurochem 62:2472-2475. Medline

Hodge JJ (2009) Ion channels to inactivate neurons in Drosophila. Front Mol Neurosci 2:13. CrossRef Medline

Hummel T, Krukkert K, Roos J, Davis G, Klämbt C (2000) Drosophila Futsch/22C10 is a MAP1B-like protein required for dendritic and axonal development. Neuron 26:357-370. CrossRef Medline

Hunt CC, Nelson PG (1965) Structural and functional changes in the frog sympathetic ganglion following cutting of the presynaptic nerve fibres. J Physiol 177:1-20. Medline

Jan YN, Jan LY, Dennis MJ (1977) Two mutations of synaptic transmission in Drosophila. Proc R Soc Lond B Biol Sci 198:87-108. CrossRef Medline

Johns DC, Marx R, Mains RE, O’Rourke B, Marbán E (1999) Inducible genetic suppression of neuronal excitability. J Neurosci 19:1691-1697. Medline

Kaneko S, Wang J, Kaneko M, Yiu G, Hurrell JM, Chitnis T, Khoury SJ, He Z (2006) Protecting axonal degeneration by increasing nicotinamide adenine dinucleotide levels in experimental autoimmune encephalomyelitis models. J Neurosci 26:9794-9804. CrossRef Medline

Kauvar LM (1982) Reduced $\left[{ }^{3} \mathrm{H}\right]$-tetrodotoxin binding in the napts paralytic mutant of Drosophila. Mol Gen Genet 187:172-173. CrossRef Medline

Keshishian H, Broadie K, Chiba A, Bate M (1996) The drosophila neuromuscular junction: a model system for studying synaptic development and function. Annu Rev Neurosci 19:545-575. CrossRef Medline

Knöferle J, Koch JC, Ostendorf T, Michel U, Planchamp V, Vutova P, Tönges L, Stadelmann C, Brück W, Bähr M, Lingor P (2010) Mechanisms of acute axonal degeneration in the optic nerve in vivo. Proc Natl Acad Sci U S A 107:6064-6069. CrossRef Medline

Kuwada JY, Wine JJ (1981) Transient, axotomy-induced changes in the membrane properties of crayfish central neurones. J Physiol 317:435461. Medline

LoPachin RM Jr, LoPachin VR, Saubermann AJ (1990) Effects of axotomy on distribution and concentration of elements in rat sciatic nerve. J Neurochem 54:320-332. CrossRef Medline

Loughney K, Kreber R, Ganetzky B (1989) Molecular analysis of the para locus, a sodium channel gene in Drosophila. Cell 58:1143-1154. CrossRef Medline

Lubińska L (1977) Early course of Wallerian degeneration in myelinated fibres of the rat phrenic nerve. Brain Res 130:47-63. CrossRef Medline

Luttges MW, Kelly PT, Gerren RA (1976) Degenerative changes in mouse sciatic nerves: electrophoretic and electrophysiologic characterizations. Exp Neurol 50:706-733. CrossRef Medline

Mata M, Staple J, Fink DJ (1986) Changes in intra-axonal calcium distribution following nerve crush. J Neurobiol 17:449-467. CrossRef Medline

McDonald WI (1972) The time course of conduction failure during degeneration of a central tract. Exp Brain Res 14:550-556. Medline

Miledi R, Slater CR (1970) On the degeneration of rat neuromuscular junctions after nerve section. J Physiol 207:507-528. Medline

Miller BR, Press C, Daniels RW, Sasaki Y, Milbrandt J, DiAntonio A (2009) A dual leucine kinase-dependent axon self-destruction program promotes Wallerian degeneration. Nat Neurosci 12:387-389. CrossRef Medline 
Moldovan M, Alvarez S, Krarup C (2009) Motor axon excitability during Wallerian degeneration. Brain 132:511-523. CrossRef Medline

Mosca TJ, Carrillo RA, White BH, Keshishian H (2005) Dissection of synaptic excitability phenotypes by using a dominant-negative shaker $\mathrm{K}+$ channel subunit. Proc Natl Acad Sci U S A 102:3477-3482. CrossRef Medline

Nelson JC, Wyman RJ (1990) Examination of paralysis in Drosophila temperature-sensitive paralytic mutations affecting sodium channels: a proposed mechanism of paralysis. J Neurobiol 21:453-469. CrossRef Medline

Nitabach MN, Blau J, Holmes TC (2002) Electrical silencing of Drosophila pacemaker neurons stops the free-running circadian clock. Cell 109:485495. CrossRef Medline

O'Dowd DK, Germeraad SE, Aldrich RW (1989) Alterations in the expression and gating of Drosophila sodium channels by mutations in the para gene. Neuron 2:1301-1311. CrossRef Medline

Osterloh JM, Yang J, Rooney TM, Fox AN, Adalbert R, Powell EH, Sheehan AE, Avery MA, Hackett R, Logan MA, MacDonald JM, Ziegenfuss JS, Milde S, Hou YJ, Nathan C, Ding A, Brown RH Jr, Conforti L, Coleman M, Tessier-Lavigne M, Züchner S, et al. (2012) dSarm/Sarm1 is required for activation of an injury-induced axon death pathway. Science 337:481484. CrossRef Medline

Press C, Milbrandt J (2008) Nmnat delays axonal degeneration caused by mitochondrial and oxidative stress. J Neurosci 28:4861-4871. CrossRef Medline

Ritzenthaler S, Suzuki E, Chiba A (2000) Postsynaptic filopodia in muscle cells interact with innervating motoneuron axons. Nat Neurosci 3:1012_ 1017. CrossRef Medline

Roos J, Hummel T, Ng N, Klämbt C, Davis GW (2000) Drosophila Futsch regulates synaptic microtubule organization and is necessary for synaptic growth. Neuron 26:371-382. CrossRef Medline

Schlaepfer WW, Bunge RP (1973) Effects of calcium ion concentration on the degeneration of amputated axons in tissue culture. J Cell Biol 59:456470. CrossRef Medline

Schwabe T, Bainton RJ, Fetter RD, Heberlein U, Gaul U (2005) GPCR signaling is required for blood-brain barrier formation in drosophila. Cell 123:133-144. CrossRef Medline

Shen H, Hyrc KL, Goldberg MP (2013) Maintaining energy homeostasis is an essential component of Wld-mediated axon protection. Neurobiol Dis 59:69-79. CrossRef Medline

Siddiqi O, Benzer S (1976) Neurophysiological defects in temperaturesensitive paralytic mutants of Drosophila melanogaster. Proc Natl Acad Sci U S A 73:3253-3257. CrossRef Medline

Stern M, Kreber R, Ganetzky B (1990) Dosage effects of a Drosophila sodium channel gene on behavior and axonal excitability. Genetics 124:133-143. Medline

Stewart BA, Atwood HL, Renger JJ, Wang J, Wu CF (1994) Improved stability of Drosophila larval neuromuscular preparations in haemolymphlike physiological solutions. J Comp Physiol A 175:179-191. CrossRef Medline

Stys PK (2005) General mechanisms of axonal damage and its prevention. J Neurol Sci 233:3-13. CrossRef Medline
Stys PK, Waxman SG, Ransom BR (1992) Ionic mechanisms of anoxic injury in mammalian CNS white matter: role of $\mathrm{Na}+$ channels and $\mathrm{Na}(+)$ $\mathrm{Ca} 2+$ exchanger. J Neurosci 12:430-439. Medline

Suzuki DT, Grigliatti T, Williamson R (1971) Temperature-sensitive mutations in Drosophila melanogaster: VII. A mutation (para-ts) causing reversible adult paralysis. Proc Natl Acad Sci U S A 68:890-893. CrossRef Medline

Tanouye MA, Ferrus A, Fujita SC (1981) Abnormal action potentials associated with the shaker complex locus of Drosophila. Proc Natl Acad Sci U S A 78:6548-6552. CrossRef Medline

Tian L, Hires SA, Mao T, Huber D, Chiappe ME, Chalasani SH, Petreanu L, Akerboom J, McKinney SA, Schreiter ER, Bargmann CI, Jayaraman V, Svoboda K, Looger LL (2009) Imaging neural activity in worms, flies and mice with improved GCaMP calcium indicators. Nat Methods 6:875881. CrossRef Medline

Titmus MJ, Faber DS (1990) Axotomy-induced alterations in the electrophysiological characteristics of neurons. Prog Neurobiol 35:1-51. CrossRef Medline

Tsao JW, George EB, Griffin JW (1999) Temperature modulation reveals three distinct stages of Wallerian degeneration. J Neurosci 19:4718-4726. Medline

Walters ET, Alizadeh H, Castro GA (1991) Similar neuronal alterations induced by axonal injury and learning in Aplysia. Science 253:797-799. CrossRef Medline

Wang JT, Medress ZA, Barres BA (2012) Axon degeneration: molecular mechanisms of a self-destruction pathway. J Cell Biol 196:7-18. CrossRef Medline

Waxman SG (2006) Axonal conduction and injury in multiple sclerosis: the role of sodium channels. Nat Rev Neurosci 7:932-941. CrossRef Medline

Wu CF, Ganetzky B (1980) Genetic alteration of nerve membrane excitability in temperature-sensitive paralytic mutants of Drosophila melanogaster. Nature 286:814-816. CrossRef Medline

Xiong X, Collins CA (2012) A conditioning lesion protects axons from degeneration via the Wallenda/DLK MAP kinase signaling cascade. J Neurosci 32:610-615. CrossRef Medline

Xiong X, Wang X, Ewanek R, Bhat P, Diantonio A, Collins CA (2010) Protein turnover of the Wallenda/DLK kinase regulates a retrograde response to axonal injury. J Cell Biol 191:211-223. CrossRef Medline

Xiong X, Hao Y, Sun K, Li J, Li X, Mishra B, Soppina P, Wu C, Hume RI, Collins CA (2012) The highwire ubiquitin ligase promotes axonal degeneration by tuning levels of nmnat protein. PLoS Biol 10:e1001440. CrossRef Medline

Zhang B, Stewart B (2010) Electrophysiological recording from Drosophila larval body-wall muscles. Cold Spring Harb Protoc 2010:pdb.prot5487. CrossRef Medline

Ziv NE, Spira ME (1993) Spatiotemporal distribution of Ca2+ following axotomy and throughout the recovery process of cultured Aplysia neurons. Eur J Neurosci 5:657-668. CrossRef Medline

Ziv NE, Spira ME (1995) Axotomy induces a transient and localized elevation of the free intracellular calcium concentration to the millimolar range. J Neurophysiol 74:2625-2637. Medline 